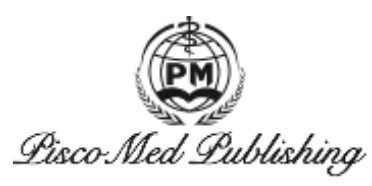

Original Research Article

\title{
New changes of world economy and China's challenges and responses
} Yajie He

China University of Political Science and Law, Beijing 100088, China; 9474343@qq.com

Abstract: China has made tremendous achievements in politics, economics and culture, which depends on the new opportunities created by the layout of new changes. The east and west have sped up the regional cooperation and accelerate the development of the free trade area, becoming an important scenery line in the global economy. Weakness in emerging markets has brought some challenges to China in the external economic environment.

Keywords: New changes in the world economy; China's economy; challenges; responses

Since the beginning of this century, the earth has changed dramatically and the complexity of the world has been added. Compared with the 20th century, not only the world population has increased sharply, but also the political pattern has changed greatly. Correspondingly, the political and economic development pattern of all countries in the world has changed a lot. In this context, China's economic development has improved under the leadership of Xi Jinping and the CPC central committee.

\section{The changing characteristics of the current world economic situation}

Starting from the end of 2016, the world economy gradually began to improve, and this situation will continue to strengthen in 2019, which is quite different from the stagnation of global economic growth with the rapid slowdown of global trade growth and the strengthening of global financial market turbulence in previous years. The world economy will grow rapidly in 2019. With the improvement of the global economy and the recovery of international trade, it is expected to improve the international financial market and greatly improve the confidence of investors in the market ${ }^{[1]}$.

\subsection{Various economies show a synchronous growth trend}

Since 2017, the global economic development has generally shown two characteristics. The first is the recovery of the global economy and trade, the steady growth of the global financial market and the good growth momentum of the global economy. Second, economic growth is universal. All regions of the world and all major economies have shown positive growth trends and achieved varying degrees of growth, especially in the developed countries, where economic growth has been faster than expected.

The International Monetary Fund (IMF) released the World Economic Outlook report in October 2019 showing that global economic growth increased to 3.6\% in 2019, surpassing the 3.2\% growth rate in 2018 (and the lowest level since the crisis). IMF believes that the global economy will have grown significantly since 2019 , when $75 \%$ of the world's economies grew at a rapid pace. The economy has grown at its fastest rate in the past decade. In addition, the Economic Outlook report issued by the Organization for Economic Cooperation and Development (OECD) on November 28, 2019 also refers to the state of global economic development, which contains a lot of information on fut-

Copyright (C) 2019 Yajie He

doi: $10.18282 /$ ff.v8i1.803

This is an open-access article distributed under the terms of the Creative Commons Attribution Non-Commercial License

(http://creativecommons.org/licenses/by-nc/4.0/), which permits non-commercial use, distribution, and reproduction in any medium, provided the original work is properly cited. 
ure economic development. According to the OECD, the economy grew by $3.6 \%$ in 2017 , which is the fastest growth rate in the past seven years. According to the report on the World Economic Situation and Prospects 2020 issued by the United Nations on December 11, 2019, nearly 2/3 of the world's economies are growing at an unprecedented rate. At present, the world economy shows relatively strong growth, in which cyclical factors play an important role. Over the years, most central banks have been implementing loose monetary policies to reduce loan costs, restore international trade, improve the investment climate and ensure economic recovery ${ }^{[2]}$.

Since 2017, especially in developed countries, the economic growth has been even more obvious, with the economies of the United States, Japan and European countries growing sharply. In these countries, the PMI is growing faster than expected, while the labor market continues to grow. Overall economic growth in developed countries is expected to reach $2.2 \%$ in $2020,0.5 \%$ higher than that in 2019 . The U.S. economy continues to grow; the labour market continues to develop; the unemployment rate will continue to decline; household consumption capacity and the purchasing power will increase; fixed assets investment will rise; the U.S. stock market overall reached a new height and returned to normal monetary policy. According to the forecast of the U.S. Federal Reserve, the U.S. economy is likely to achieve a $2.5 \%$ growth rate in 2019 . As manufacturing continues to develop and domestic demand continues to grow, the euro economy will exceed expectations in 2017, and the economic growth will return to the level before the international financial crisis, which has become a national economic flash point. The European Commission expects the eurozone economy to grow by $2.2 \%$ in 2019 , the fastest rate in a decade. Driven by global economic growth, Japan's economy, which relies on external demand, continued to grow in 2019 , with a whole year growth rate of $1.9 \%$, mainly due to increased global demand and the contribution of imports and exports to the economy. With economic growth and a shortage of labour, the unemployment rate in Japan (2.7\% in November 2019) has fallen to its lowest level since December 1994.

A favorable economic condition, stable changes in trade prices, and strong growth in developed countries will also accelerate economic growth in emerging markets and developing countries in 2020. The global economic growth is expected to reach $4.6 \%$ in $2020,0.3 \%$ higher than in 2016. China's economic performance has been paid close attention, and the annual growth rate is expected to be $6.9 \%$. China's economy will continue to develop at a medium-high speed, whose growth contribution rate to the global economy cannot be ignored. Under the influence of the reform in the goods and services tax, India's economy grew by about $6.7 \%$, with a rapid economic growth rate. Russia continues to emerge from the recession and its economy continues to grow. Russia's economy is expected to grow by about $2 \%$ in 2020. As a representative of the energy-dependent economy, Russia's economic recovery depends to a large extent on rising commodity prices, particularly as international oil prices have reached their highest levels since 2015 due to a shortage of oil-producing countries. The Brazilian economy has also emerged from recession, with an economic growth rate of $0.7 \%$ in 2019 , while South Africa's economic growth continues to be slow and the development of industrial structure is uneven

\subsection{Recovery rate of global transnational investment has improved slightly}

Global trade has been growing more slowly than the economy for years. The role of trade as an engine of economic growth is diminishing. Since 2019, the global economy has been accelerating with more active world trade activities and risen commodity prices, and the increase in the speed of international trade has effectively alleviated the decline in the growth rates. The growth in global trade is mainly due to the recovery in Asian trade and the growth in demand of North America and Europe. Since 2017, most of the countries/regions have reversed the decline in growth since last year and achieved rapid growth of imports and exports. By contrast, the EU import and export is almost zero in 2016, which grew by more than $7 \%$ in the first three quarters of 2017. The recovery in exports is the main cause of economic growth, and strong domestic demand has accelerated import demand. The growth in imports and exports in the United States, Japan and the euro zone also indicates that the external demand environment in both markets is improving. After two years of negative growth, China's export growth in 2019 reached its highest level in the past four years. 


\subsection{Global monetary policy tends to tighten}

After the 2008 international financial crisis, every country's Central Bank injected too much liquidity into the market. With the rapid economic growth in each country, the United States, Japan and other countries have gradually withdrawn from loose monetary policies to tight monetary policies. Currently, the federal financial target rate has been raised from $1.25 \%$ to $1.5 \%$. Meanwhile, in October 2019, the balance sheet reached $\$ 4.5$ trillion (the Fed cut its holdings of treasuries and mortgage-backed securities). In 2017, Central Banks in other major countries gradually showed signs of normalizing monetary policy. On October 26, the European Central Bank (ECB) announced that it would continue to support the current zero interest rate policy in euro area and reduce its monthly asset purchases from $€ 60$ billion to $€ 300$, which has been reduced since January 2018. The Central Bank of the UK announced that it would raise its benchmark interest rate by $0.25 \%$ or $0.5 \%$, from November 2 . This is the first monetary policy proposed by the Central Bank of the UK since July 2007. Although the Central Bank of Japan did not mention withdrawal from loose monetary policy, it has reduced the size of its bond purchases and discussed strategies to withdraw from loose monetary policy. In addition, Central Banks in Canada, South Korea and other countries have also adopted tight monetary policy. Correspondingly, global monetary policy has gradually become tighter in 2017.

\subsection{The trade growth model is facing challenges in many aspects}

With the new round of scientific and technological revolution promoting the continuous deepening and diffusion of the global value chain, the broader global cooperative network has made important contributions to trade scale growth and economic development. However, it should not be ignored that the developing countries represented by China, which participate in the international division of labor in the form of traditional processing trade, have not achieved simultaneous improvement in trade growth and benefits. Its low-cost trade growth model faces many tests. In this context, the transformation and upgrading of China's economy is extremely urgent. And the report of the 19th CPC National Congress clearly pointed out that "to promote China's industry to move towards the medium-high end of the global value chain, and cultivate a number of world-class advanced manufacturing clusters." In recent years, China has rapidly and deeply participated in the global production network. While its economic strength is increasing, it is facing the dual competition of "re-industrialization" of developed countries and "low-cost advantage" of developing countries. In particular, the trade war between China and the United States has been escalating in the past two years, indicating that it is particularly important to promote industrial restructuring to achieve the rise of the value chain and the improvement of the division of labor.

\section{Challenges brought by new economic changes to China's external economic environment}

\subsection{Loose monetary tends to lead to inflation}

Since the 2008 crisis, the US has introduced a number of looser policies rules. In the wake of the European debt crisis, the European Central Bank cut interest rates and then launched the 'Direct Currency Exchange Program', and announced unlimited purchases of government bonds in eurozone members. In the first half of this year, Japan's Abe cabinet also launched unlimited loose monetary policy, which is one way to deal with the high levels of debt in the western developed world and has no ceiling in Europe and the United States. The United States has set a limit on the amount of bonds it can purchase per month, but with no end date, meaning there is no limit on the total amount of money the European Central Bank can trade. Despite these restrictions, there are no restrictions on the purchase of financial assets in Japan.

This unprecedented loose monetary policy has boosted market confidence in the short term, alleviated the European debt crisis and brought some funds to the real economy, but it has not effectively solved the structural problems of economic growth. In general, if an indebted country uses currency controls as a way to ease its debts, creditors will be hit by shrinking debt rights and currency disorder. Now, the economic policy effect of QE has led to 
stock price bubbles and "competitive falls" in exchange rates, most costs of which must be borne by some developing countries. In the long run, as loose monetary policy continues, global liquidity and trade will expand, thus exacerbating global inflationary pressures.

The current complex world monetary system gives China large foreign exchange reserves and US Treasuries. With the development, it is important to fully assess the potential risks of future currencies and put forward countermeasures. For China, in the economic and political environment at home and abroad, the RMB enjoys a small appreciation trend. In the future, the RMB exchange rate system should be reformed, along with maintaining the control of exchange rate and capital flow, to prevent the instability of China's financial system caused by the rapid entry and exit of international capital $^{[3]}$.

\subsection{The strategy of free trade zone of western countries may affect China's share of foreign trade}

Since the high-profile participation of the United States in the negotiations, the expansion of member States has marked the rapid development of the global economy and trade strategy. In other words, taking promoting the two main negotiations as the goal, doubling trade as the high-level goal of the trade mechanism, and regional trade as the leading, the goal of building a new global trade pattern can be ultimately achieved. In terms of medium- and long-term policy objectives, the strategy focuses on achieving U.S. economic growth, especially by doubling U.S. exports and increasing employment in the U.S. to change the slow pace of economic recovery. This shows that the global balance strategy of the United States includes not only security and political elements, but also the direction in which the world economy will be shaped in the future.

Many actions of the United States, such as hindering the economic integration of East Asia, are due to the strategic hindrance to China through mechanism hegemony, instead of normal competitive means. Under these conditions, there will be challenges to the prospects for free trade negotiations between China and Japan and South Korea. In the future, the establishment of regional economic strategy in China requires more objective, comprehensive and long-term thinking.

With the reform and entry into the WTO, China has actively participated in the division of labor in the global value chain and become a veritable "world factory". Its total import and export trade have increased from 20.6 billion US dollars in 1978 to 3.6855 trillion US dollars, especially after China entered the WTO in 2001. Sino-US trade has grown rapidly and is a major import and export partner to each other. However, as a developing country dominated by processing trade, China's total exports are seriously overestimated under the method of customs statistics. The current bilateral economic and trade friction initiated by the United States is based on the huge trade deficit between these two countries. From trade war to industrial chain war and technological war, the fundamental reason is that Trump believes that China's division of labor in the global value chain has posed a threat and challenge to the United States.

\subsection{The intensification of protectionism may lead to the increase of China's foreign trade and economic friction}

Due to the sluggish growth of the world economy, especially the continuous economic slowdown between developed and emerging economies, China's export trade environment is still relatively poor, mainly reflected in the increasing trade frictions in China, which makes it difficult to maintain constant external demand. In this regard, China has implemented necessary countermeasures in accordance with the current provisions of the World Trade Organization. At the same time, China should promote changes of the foreign trade development mode, improve the export trade and the quality of export products, promote their own brands and proprietary channels, improve the after-sales service system, stable and extend new market. The government should be committed to working with industry cooperation, to deal with trade frictions and protect the legal rights and interests of Chinese enterprises. 


\section{China should actively respond to the new changes in the world economy}

\subsection{Implement the concept of new development and promote high-quality development of the Chinese economy}

China's economy is entering a phase of rapid and high-quality growth. The high quality and rapid development of China's economy is the fundamental guarantee for China to formulate development plans and implement policy regulation in the future development process. At present, the most important historical mission is to deepen the concept of the new development. First of all, China should adhere to quality first, give priority to efficiency, promote supply-side reform, constantly improve the adjustment of its economy and modern economic system, promote China's economic structure and industrial upgrading, create new advantages for global competition, and meet the challenges of the global economic recession and global structural adjustment. As for foreign trade, China should promote high-quality economic development, change the mode of trade and investment, and actively promote the import and export trade. In addition, China should cooperate with other countries to improve its competitive advantages in the international market. There is a large gap in the level of value-added output between China and the United States, so China should vigorously develop manufacturing services, promote the coordinated development of manufacturing and service industries, and make use of the industrial advantages of different intensive characteristics of service industries to promote the development of manufacturing industry. It is necessary to promote market-oriented principle, encourage enterprises to increase R \& D investment, enhance the domestic value-added benefit capacity of the manufacturing industry, and jointly enhance China's interest status in the global value chain.

\subsection{Deepen supply-side structural reform and speed up the transformation of new and old kinetic energy}

The primary condition for China to accelerate the modernization is supply-side reform. Through comprehensive and deep reform, it is necessary to overcome the institutional obstacles that hinder economic growth, accelerate the cultivation of new kinetic energy, and raise people's understanding of the sustainable transformation of new and old kinetic energy. China will actively promote supply-side reform in order to improve and optimize the business environment, especially to speed up the reform of the fiscal and tax system, carry out the policy of fee reduction and reduction, lighten the burden of enterprises, reduce institutional costs, stimulate market vitality and create an attractive international and legalized business environment. To this end, China needs to deepen the reform of foreign trade supply-side structure, provide new impetus for foreign trade and international market structure, promote market layout, speed up the transformation and upgrading of foreign trade, attach importance to improving the quality and added value of exports, promote China's transformation from a major trading country to a trading power, continue to promote trade pilot reform, and greatly reduce market access restrictions. It is also necessary to promote foreign investment and business expectations, optimize regional opening, accelerate the opening up in the western region, and increase the scale of the construction of old industrial bases in the central and western regions and northeast China. Other countermeasures include increasing investment in services to promote the transformation and upgrading of traditional manufacturing industries, encouraging enterprises to actively develop new trade in services such as product technology research and development and after-sales value-added services, and enhancing the division of labor status of the service industry in the global value chain.

\subsection{Continue to seek innovative growth, excavate and cultivate new momentum of development}

In the long run, the transition from scientific and technological revolution to commercialization is a critical period of transformation for the global economy. The global economy is changing, and so is the development process. Reform and innovation are the direction for all countries to deal with challenges and pursue development. It is clear that the new era of technological and industrial revolution has come, with the development of digital economy and shared economy, 
rising of new technologies such as artificial intelligence and quantum science, emergence of new industries, new models, and new formats, and continuous growth of new momentum of development. China should seize the opportunity of global economic change, regard innovation as the first engine of development, focus on the development of the whole country, and promote the change and upgrading of China's economy. It must strictly implement the development strategy. With an open perspective and vision, China should remove all institutional barriers unrelated to change, create growth through change, maintain competitiveness and enhance competitive advantage through continuous economic changes ${ }^{[4]}$. In view of the advantages of Chinese manufacturing industry in terms of the complexity of production structure and deep participation in the global production network, Chinese manufacturing industry can choose the global value chain climbing path of complex product integration industry and upgrade in technological R \& D and complex production integration capabilities.

\subsection{Speed up the construction of a new system of open economy and promote the formation of a new pattern of all-round opening up}

Promoting reform and development is an important experience for China's economic recovery to achieve new results. The 19th National Congress of China proposed that it is necessary to actively participate in the process of economic globalization and develop a high-quality open economy. China should strengthen the construction of "Belt and Road Initiative", promote economic development in surrounding areas, and finally achieve common development, improve liberalized trade and investment, relax market access rules, and provide pioneering services to the outside world. In order to ensure that the legitimate rights and interests of foreign-funded enterprises can be protected, it is necessary to enhance the autonomy of the reform by promoting the reform of the free trade area, promote the smooth development of the relevant work in the trade area, promote the signing of free trade and investment agreements with the countries concerned, promote the establishment of the Asia-Pacific free trade area, and promote the conclusion of negotiations on regional cooperation agreements as soon as possible and build a world free trade area network.

\subsection{Pay close attention to risk factors in the world economy and promptly address potential impacts}

China's economy continued to grow faster than expected in 2017, inspired by supply-structure reforms and accelerating global growth. However, there is a lot of pressure behind steady economic growth. Looking ahead to 2018 , there must be a deeper understanding of the complexities and changes in the global economy. While assessing the continued prosperity of the global economy, China needs to fully understand and always be fully prepared for the uncertainty of the global economy and to establish and improve preventive mechanisms to effectively prevent and address potential risks and impacts in a timely manner, particularly needs to protect itself from world political expectations from the possible impact of interest rate cuts and tax cuts by the United States. It is necessary to monitor changes in the international economy and financial markets, as well as international capital flows that may trigger, and respond actively to global economic frictions. It should be noted that many of the trade investigations Trump launched against China in 2017 ended in 2018, and it is uncertain what sanctions the US will impose, which requires more attention and vigilance.

\section{Conclusion}

Generally speaking, the changes in the world pattern have brought opportunities and new challenges to China's economic development. Under this macro background, China must make every effort to promote the construction of socialism with Chinese characteristics and enter the decisive stage of a well-off society in China. The direction of China's economic development is green sustainable development. On the basis of emphasizing the quality and interests of development, China should take green development as the foundation, explore new ways of economic development in the course of the changes of the world economy, and ensure a qualitative leap in economic development. 


\section{References}

1. Li L. The development direction of China's economy in the new era under the background of new changes in the world pattern (in Chinese). China Business \& Trade 2018; (19): 167-168. doi: 10.19699/j.cnki.issn2096-0298.2018.19.167.

2. Lu Y. The new changes of the current world economic situation and China's countermeasures: An analysis and prospect in 2018 (in Chinese). Journal of International Economic Cooperation 2018; (1): 12-17.

3. Han B. New changes in the world economic pattern and the transformation of China's economic development mode (in Chinese). World Shipping 2014; 37(5): 5-11.

4. Jiang Y. New changes in the world economy and challenges faced by China (in Chinese). International Studies, 2014; (1): 115-125. 